\title{
GAMBARAN PELAKSANAAN ASESMEN PASIEN NARKOTIKA DI RUMAH SAKIT JIWA ATMA HUSADA MAHAKAM PROVINSI KALIMANTAN TIMUR TAHUN 2018
}

\author{
Herry Farjam ${ }^{1}$, Rindha Mareta Kusumawati ${ }^{2}$, Wahyudin ${ }^{3}$ \\ Herryfarjam86@gmail.com \\ rindhamaretakusumawati@gmail.com \\ wahynur603@gmail.com
}

\begin{abstract}
ABSTRAK
Penanganan pasien narkotika dan psikotropika dengan asesmen baik berupa pemeriksaan fisik, psikis, diagnosis dan rehabilitasi yang pada keputusan akhirnya apakah pasien di rawat inap atau rawat jalan pada hakikatnya semua aturan yang diberlakukan pihak manajemen Rumah Sakit Jiwa Atma Husada sesuai standar yang berlaku.Jenis penelitian ini merupakan penelitian observasional yang berbentuk deskriptif kualitatif. Subjek penelitian sebanyak 5 orang dengan teknik pengambilan informan dengan menggunakan purposive sampling. Analisis data menggunakan pendekatan Milles dan Huberman. Hasil penelitian menjelaskan bahwa asesmen pemeriksaan fisik masih belum sesuai dengan S.O.P dikarenakan tidak semua pasien dilakukan pemeriksaan jantung, sedangkan pemeriksaan THT semua pasien dilakukan pemeriksaan. Asesmen pemeriksaan psikis sudah sesuai S.O.P hanya saja pasien narkotika kurang terbuka terhadap petugas terkait permasalahannya sehingga menjadi salah satu masalah yang dialami oleh petugas untuk mengetahui tingkat depresi dan rasa cemas pasien narkotika. Diagnosis dokter sudah sesuai S.O.P dan hasilnya pasien lebih banyak menggunakan opium. Rehabilitasi pasien narkotika sudah sesuai S.O.P dan rehabiltasi rawat inap paling banyak dilakukan kepada pasien narkotika. Diharapkan pihak rumah sakit memberikan gambaran secara jelas terkait pelaksanaan asesmen dan pasien hendaknya terbuka saat dilakukan asesmen.
\end{abstract}

Kata Kunci : asesmen, pasien, narkotika

\begin{abstract}
Assessments Handling of narcotics and psychotropic patients in physical Assessment, psychological, diagnostic and rehabilitation examinations and final decision whether patients are hospitalized or outpatient are basically all the rules imposed by the management of the Atma Husada Mental Hospital based on the applicable standards. This study was qualitative descriptive research with observational approach. The research subjects were 5 people or informant by using purposive sampling techniques. Interactive design of Milles and Huberman is used as Data analysis technique in this research. The results showed that the physical examination assessment was still not based on Standard Operating Procedure (SOP) because not all patients were examined for a heart, while the ENT examination of all patients was examined. Assessment of psychological examination is based on SOP but narcotics patients are less open to officers about their problem so it's one of the problems experienced by officers to determine the level of depression and anxiety of narcotic patients. The doctor's diagnosis is also based on SOP. The patient uses more opium as one of the results. Rehabilitation of narcotics patients is already based on SOP and rehabilitation of hospitalizations is mostly carried out for narcotics patients. It is expected to the hospital to provide a clear description of the implementation of the assessment and the patient should be open when conducting an assessment.
\end{abstract}

Keywords: assessment, patients, narcotics 


\section{PENDAHULUAN}

\section{A. Latar Belakang}

Penyalahgunaan psikotropika telah menjadi issu yang telah mengglobal di mana hal ini telah tercatat dalam sidang umum terakhir yang diadakan ICPO (International Criminal Police Organization) yang ke 66 pada Tahun 1997 di India yang diikuti seluruh anggota yang berjumlah 177 negara dari benua Amerika, Asia, Eropa, Afrika, dan Australia, bahwa peredaran ecstacy mencapai 400 milyar dollar AS. (Taufik, dkk, 2003).

Berdasarkan data dari BNN-RI pengguna narkoba di Indonesia setiap tahunnya mengalami kenaikan pada tahun 2013 terdapat 3,6 juta orang atau 2,6\% dari populasi penduduk berusia 10-59 tahun. Tahun 2014 terdapat 4,1 juta orang atau $2,25 \%$ dari total semua penduduk Indonesia dan pada tahun 2015 terdapat 5,6 juta orang di provinsi DKI Jakarta terbesar yang menggunakan narkoba terbesar (BNN RI, 2016).

Menurut Badan Narkotika Nasional Provinsi Kalimantan Timur pengguna narkoba tahun 2013 berjumlah 77.884 orang, Tahun 2014 sebanyak 97.000 orang $(2,1 \%)$ dan pada tahun 2015 mencapai 118.923 orang $(2,52 \%)$ pengguna berasal dari kalangan remaja dan pelajar / mahasiswa. Samarinda termasuk wilayah kerja BNNP Kaltim, dimana Menurut data BNNP Kaltim termasuk peringkat pertama pengguna narkotika terbanyak setelah Balikpapan dan Tarakan (BNNP Kaltim, 2016).

Upaya yang dilakukan oleh BNNP Kaltim dalam melakukan pemberantasan narkoba di wilayah Kalimantan Timur yaitu dengan melaksanakan rehabilitasi. Sesuai dengan undangundang nomor 35 tahun 2009 tentang narkotika dalam pasal 54 tentang narkotika, pecandu narkotika dan korban penyalahgunaan narkotika wajib menjalankan rehabilitas medis dan sosial. Menurut data Rumah Sakit Jiwa Daerah Atma Husada Mahakam Provinsi Kalimantan Timur pada tahun 2013 jumlah residen adalah pasien yang di rehabilitasi rawat jalan sebanyak 144 orang sedangkan rawat inap 130, Pada tahun 2014 jumlah residen rehabilitasi rawat jalan sebanyak 226 orang dan rawat inap 220 orang. Pada tahun 2015 jumlah residen rehabilitasi rawat jalan sebanyak 296 orang dan rawat inap 280 orang (Rekam Medik RS. Jiwa Daerah Atma Husada Mahakam, 2016).

Penanganan bagi korban narkotika dan psikotropika dengan asesmen baik berupa pemeriksaan fisik, psikis, diagnosis dan rehabilitasi yang pada keputusan akhirnya apakah pasien di awat inap atau rawat jalan pada hakikatnya semua aturan yang diberlakukan pihak manajemen Rumah Sakit Jiwa Atma Husada sesuai standar yang berlaku. Pelaksanaan asesmen pasien narkotika tidak lepas dari peningkatan kinerja disuatu Rumah Sakit yang merupakan gambaran dari keseriusan berbagai pihak termasuk dokter, perawat dan tenaga medis dalam menjalankan proses keperawatan kepada pasien secara optimal.

\section{B. Rumusan Masalah}

Berdasarkan uraian diatas peneliti ingin mengetahui "Gambaran Pelaksanaan Asesmen Pasien Narkotika di Rumah Sakit Jiwa Daerah Atma Husada Mahakam Provinsi Kalimantan Timur?"

\section{Metode Penelitian}

Jenis penelitian ini merupakan penelitian observasional yang berbentuk deskriptif kualitatif merupakan penelitian yang bertujuan hanya menggambarkan fenomena yang ditemukan baik berupa faktor risiko, efek atau hasil. Data tersebut disajikan apa adanya tanpa dianalisis bagaimana dan mengapa fenomena tersebut dapat terjadi (Santoso, 2009). Dengan demikian pada penelitian yang bersifat deskriptif tidak perlu ada hipotesis dengan mendeskripsikan sejumlah variabel tentang gambaran alur pelaksanaan asesmen pasien narkotika di Rumah Sakit Jiwa Daerah Atma Husada Mahakam Samarinda.

Desain penelitian yang digunakan dalam penelitian ini adalah pendekatan pada Studi Kasus yang merupakan suatu metode untuk menyelidiki atau mempelajari suatu kejadian mengenai perorangan (riwayat hidup). Pada metode studi kasus ini diperlukan banyak informasi guna mendapatkan bahan-bahan yang luas (Nursalam, 2011). 
p-ISSN 2460-0350

e-ISSN 2477-5819

JURNAL KESMAS UWIGAMA

\section{HASIL DAN PEMBAHASAN}

\section{Asesmen Pemeriksaan Fisik}

Berdasarkan hasil wawancara yang dilakukan oleh penulis terhadap pasien narkotika dan petugas kesehatan yang berada di Rumah Sakit Jiwa Daerah Atma Husada Mahakam bahwa bahwa pemeriksaan fisik masih belum sesuai S.O.P. Semua anggota tubuh dilakukan pemeriksaan akan tetapi ada beberapa pemeriksaan seperti jantung tidak dilakukan dan pemeriksaan THT, kulit, pencernaan,saraf pusat dan pembuluh darah masih dilakukan kepada pasien

\section{Asesmen Pemeriksaan Psikis}

Berdasarkan hasil wawancara diatas dapat disimpulkan bahwa pemeriksaan psikis tidak serumit pemeriksaan lainnya, pasien yang sudah mendaftar,yang telah melakukan pemeriksaan fisik, kemudian akan dilakukan konseling berupa pemeriksaan psikis, setelah itu baru akan hasil pemeriksaan psikis akan diserahkan ke dokter untuk dilakukan langkah selanjutnya dan hal ini sudah sesuai S.O.P. Pemeriksaan psikis berupa bimbingan konseling, dilakukan pemahaman lebih lanjut secara bertahap agar pasien merasa nyaman untuk terbuka, baru akan dilakukan konseling lebih mendalam, terkait pasien memiliki rasa cemas dan depresi hal ini tersirat dari rasa takut saat diajukan.

\section{SIMPULAN}

Asesmen pemeriksaan fisik masih belum sesuai dengan S.O.P dikarenakan tidak semua pasien dilakukan pemeriksaan jantung, sedangkan pemeriksaan THT semua pasien dilakukan pemeriksaan.

Asesmen pemeriksaan psikis sudah sesuai S.O.P hanya saja pasien narkotika kurang terbuka terhadap petugas terkait permasalahannya sehingga menjadi salah satu masalah yang dialami oleh petugas untuk mengetahui tingkat depresi dan rasa cemas pasien narkotika.

Pihak Rumah Sakit seharusnya memberikan penjelasan mengenai asesmen fisik dan psikis terhadap pasien dengan memberikan gambar dipintu masuk loket pendaftaran sehingga tidak ada pasien yang masih kebingungan saat pertama kali berkunjung.

\section{DAFTAR PUSTAKA}

Rekam Medik RS. Jiwa Daerah Atma Husada Mahakam. 2016. Laporan Data Kunjungan
Volume 4, Nomor 2, 2018

Pasien Rawat Inap dan Rawat Jalan. Rumah Sakit Atma Husada, 2013, 2014, 2015.

Nursalam. 2011. Konsep dan Keperawatan Metodologi Penelitian Ilmu Keperawatan. Jakarta: Salemba Medika.

Santoso, S. 2009. Metodelogi Penelitian Biomedis. Jakarta. Bina Rupa Aksara.

Taufik, dkk. 2003. Tindak Pidana Narkotika. Jakarta : Ghalia Indonesia 